\title{
Real-time Simulation of Photovoltaic Generation System Based on dSPACE
}

Xiaobo YANG ${ }^{1, a}$, Qingduo $\mathrm{YIN}^{2, \mathrm{~b}}$, Jihong QIAN ${ }^{3, c}$, Ying $\mathrm{CHEN}^{4, \mathrm{~d}}$, Xiaoyu $\mathrm{XI}^{5, \mathrm{e}}$ ${ }^{1}$ Electric Power Research Institute, State Grid JIBEI Electric Power Co., Ltd, Beijing, 100053, China

${ }^{2}$ Electric Power Research Institute, State Grid JIBEI Electric Power Co., Ltd, Beijing, 100053, China

${ }^{3}$ Wasion Group, Changsha, 410205, China

${ }^{4}$ School of Electrical Engineering, Xi'an Jiaotong University, Xi'an, 710049, China

${ }^{5}$ Electric Power Research Institute, State Grid JIBEI Electric Power Co., Ltd, Beijing, 100053, China

a email:13811909550@163.com, ${ }^{b}$ email: yin.qingduo@nc.sgcc.com.cn,

cemail: 18605677@qq.com, d email:ying.zc.g@gmail.com, ${ }^{\mathrm{e}}$ xi.xiaoyu@nc.sgcc.com.cn

Keywords: Photovoltaic Power Generation System; MATLAB/Simulink; Real-time Simulation; dSPACE; Hardware-in-the-loop Simulation

Abstract. A detailed simulation model of Photovoltaic (PV) generation system based on MATLAB/Simulink and the detailed mathematical presentation, is established first. Its inverter-based simplified model, i.e. the switching-function equivalent model is proposed and simulated, overcoming the limit of traditional methods in simulation speed. The real-time simulation platform based on dSPACE and DSP controller is established, and its validity and utility are assessed by evaluating the system performance under solar irradiance/temperature disturbance.

\section{Introduction}

Solar energy does not only preserve traditional fuel resources but also reduces pollution significantly by generating clean energy. With the decrease in the price of PV modules and the world-wide governmental renewable energy targets, it is becoming a worldwide trend to increase the penetration level of grid-connected PV systems. However, this high penetration level of PV might impact system operations and cause stability problems [1], hence the need arises for detailed system studies of PV plant design and its interconnection with the transmission and distribution systems. A well-defined real-time simulation model would be of great help in this task.

In order to meet the needs described earlier, several factors need to be considered: 1 ) effect of environmental variables like solar irradiation, temperature of the system should be represented; 2) effective control strategy for the system need to be implemented and 3) the simulation system has to be fast enough to guarantee real-time operation: this means that the simulation model should be simplified as much as possible while preserving enough accuracy, meanwhile the hardware platform should be powerful in implementing the model.

Previous works on the real-time simulation of PV power generation connected to power system have been presented by other authors (for example, [2,3,4]). However, few works are done based on the dSPACE platform. Meanwhile, some of them fails to meet the above needs.

This paper focuses on modeling and real-time simulation of a grid-connected PV system and is organized as follows. Firstly, the studied PV power system is modeled in detail, including the power circuit and control part. The switching-function equivalent model of inverter is proposed such as to simplify the system model. Finally, the real-time simulation platform based on dSPACE and DSP controller is established, and, thus, presenting a highly effective way to study system behavior satisfying all the aforementioned needs.

\section{Structure of Grid-connected PV System}

In this section, the topology of studied grid-connected PV system is established and described. 
The models of PV arrays and three-phase inverter with its controller are presented.

The studied PV power system consists of PV arrays, a DC-side capacitor (see Fig. 1, $C_{d c}$ ), a three-phase DC/AC inverter with its controller and a linking inductor. This PV generation unit is connected to power system through a step-up transformer and transmission line, as shown in Fig. 1.

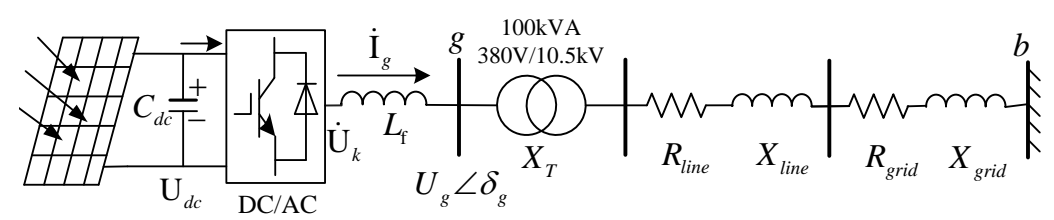

Fig.1. Topology of studied PV system

In Fig. $1, U_{d c}$ and $\dot{U}_{k}$ are the DC-side voltage and output voltage phasor of inverter, respectively. $\dot{I}_{g}$ is the current phasor of the inverter output; $U_{g}$ and $\delta_{g}$ are the voltage amplitude and phase of bus $g$, respectively. $L_{f}$ is the linking inductance; $X_{T}$ is the equivalent reactance of the transformer. $R_{\text {line }}, X_{\text {line }}, R_{\text {grid }}$ and $X_{\text {grid }}$ are the equivalent resistance and reactance of the transmission line and the power system, respectively. $b$ is an infinite bus with voltage phasor $1 \angle 0^{\circ}$.

\section{Modeling of Grid-connected PV System}

Modeling of PV Modules. For sake of simplicity, a simplified model of PV arrays [5], which is easy to implement and suitable for both theoretical analysis and practical use, is utilized instead of the classical single-diode model. Four characteristic parameters of the PV array under standard test condition $\left(S_{r e f}=1000 \mathrm{~W} / \mathrm{m}^{2}, T_{r e f}=25^{\circ} \mathrm{C}\right)$, i.e. the short circuit current $I_{\text {scref }}$, the open circuit voltage $U_{\text {ocref }}$ and the current and voltage at maximum PV power output $I_{\text {mref }}$ and $U_{\text {mref }}$, are employed in this model. In a general case, the output current of PV arrays can be expressed as:

$$
I=I_{\text {sc }}\left[1-C_{1}\left(\mathrm{e}^{U /\left(C_{2} U_{\mathrm{oc}}\right)}-1\right)\right]
$$

where $C_{1}=\left(1-I_{\text {mref }} / I_{\text {scref }}\right) e^{-U_{\text {mref }} /\left(C_{2} U_{\text {ocref }}\right)}, C_{2}=\left(U_{\text {mref }} / U_{\text {ocref }}-1\right) /\left[\ln \left(1-I_{\text {mref }} / I_{\text {scref }}\right)\right]$.

Under nonstandard conditions, the four parameters of PV module $\left(I_{s c}, U_{o c}, I_{m}\right.$ and $\left.U_{m}\right)$ can be acquired by

$$
\left\{\begin{array}{l}
I_{s c}=I_{\text {scref }}\left[1+a\left(T-T_{\text {ref }}\right)\right] \cdot S / S_{\text {ref }} \\
U_{o c}=U_{\text {ocref }}\left[1-c\left(T-T_{\text {ref }}\right)\right] \ln \left[e+b\left(S / S_{\text {ref }}-1\right)\right] \\
I_{m}=I_{\text {mref }}\left[1+a\left(T-T_{\text {ref }}\right)\right] \cdot S / S_{\text {ref }} \\
U_{m}=U_{\text {mref }}\left[1-c\left(T-T_{\text {ref }}\right)\right] \ln \left[e+b\left(S / S_{\text {ref }}-1\right)\right]
\end{array}\right.
$$

where, $T_{\text {air }}$ is the ambient air temperature; $k$ is the temperature coefficient with typical value $0.03^{\circ} \mathrm{C} \cdot \mathrm{m}^{2} / \mathrm{W} ; e=2.71828 ; a, b, c$ are correction factors that take the value $0.0008 /{ }^{\circ} \mathrm{C}, 0.2$ and $0.005 /{ }^{\circ} \mathrm{C}$, respectively.

Three-Phase Inverter and Its Simplification. The three-phase PWM inverter (see Fig. 2(a)) is utilized in the studied PV system. Two simplified models of three-phase inverter, which is one of the major components in PV system with complicated control scheme, are available based on the simplification of three-phase bridge [6,7]:

1) Switching-Function type equivalent model: This model uses the same firing pulses as for other power electronic devices and ideal switches are assumed. Accordingly, it correctly represents harmonics normally generated by the bridge and effectively improves the simulation speed.

2) Average-model based VSC: in this model, average-model type of voltage source converter is used to represent the power-electronic switches, and it uses the reference signals representing the average voltages generated at the $a b c$ terminals of the bridge. This model does not represent harmonics, and it can be used with larger sample times while preserving the average voltage 
dynamics.

In this paper, the switching-function based inverter model [8] is utilized to achieve real-time simulation with high precision. Define the switching function of a inverter leg as $S_{k}(k=\mathrm{a}, \mathrm{b}, \mathrm{c})$, it is

$$
S_{a}=S_{a}^{+}-S_{a}^{-}, \quad S_{b}=S_{b}^{+}-S_{b}^{-} \quad \text { and } \quad S_{c}=S_{c}^{+}-S_{c}^{-}
$$

where $S_{a}^{+}, S_{b}^{+}$and $S_{c}^{+}$are the switching status of upper half-legs, respectively, and $S_{a}^{-}, S_{b}^{-}$, $S_{c}^{-}$are the switching status of lower half-legs, respectively.

The three-phase voltages between inverter and point $o$ can be obtained as

$u_{a o}=\frac{1}{2} U_{d c} \cdot S_{a}, \quad u_{b o}=\frac{1}{2} U_{d c} \cdot S_{b} \quad$ and $\quad u_{c o}=\frac{1}{2} U_{d c} \cdot S_{c}$

Accordingly, the three-phase output phase voltages of inverter are

$$
u_{a n}=u_{a o}-u_{n o}, \quad u_{b n}=u_{b o}-u_{n o} \quad \text { and } \quad u_{c n}=u_{c o}-u_{n o}
$$

where $u_{n o}=\frac{1}{3}\left(u_{a o}+u_{b o}+u_{c o}\right)$.

The three-phase output currents are represented as

$$
i_{a}=i_{S 1}+i_{S 4}, \quad i_{b}=i_{S 3}+i_{S 6} \quad \text { and } i_{c}=i_{S 5}+i_{S 2}
$$

where, $i_{S 1}=i_{a} \times S_{a}^{+}, i_{S 3}=i_{b} \times S_{b}^{+}$and $i_{S 5}=i_{c} \times S_{c}^{+}$are the currents flowing on upper half-legs; $i_{S 4}=i_{a} \times S_{a}^{-}, \quad i_{S 6}=i_{b} \times S_{b}^{-}$and $i_{S 2}=i_{c} \times S_{c}^{-}$are the currents flowing on lower half-legs.

Accordingly, the dc-side current of inverter can be represented as

$$
i_{d c}=i_{S 1}+i_{S 3}+i_{S 5}
$$

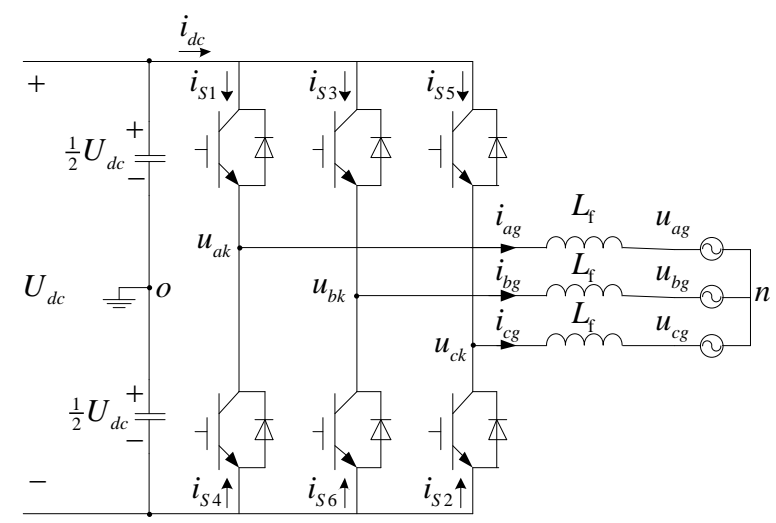

(a) Three-phase SPWM inverter

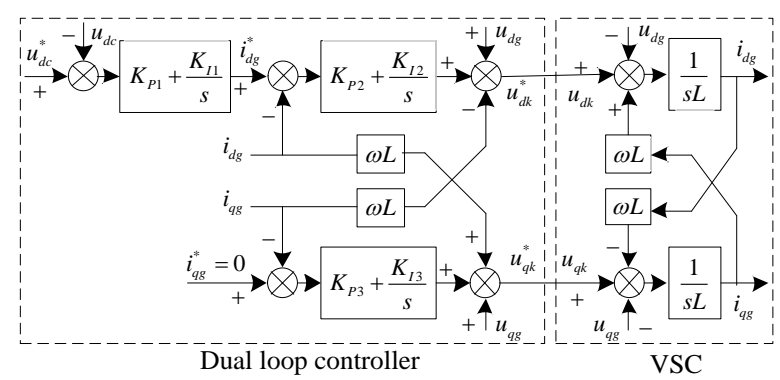

(b) diagram of dual-loop controller

Fig.2. Three-phase SPWM inverter and its controller

Modeling of Controller. The inverter control is achieved in rotational reference frame ( $d-q$ frame). The $d$ axis reference is set at the position of the voltage phasor $\dot{U}_{g}$, i.e. $u_{q g}=0$, to obtain unit power factor. Dual loop control is used in the controller (see Fig. 2(b)): outer voltage loop tracks the maximum power point of the PV panel by specifying the DC-side voltage to its corresponding reference, and two inner current loops are utilized to obtain a correct real/reactive current output. A proportional-integral (PI) controller is used in each loop; $K_{P 1}, K_{P 2}, K_{P 3}, K_{I 1}, K_{I 2}$, and $K_{I 3}$ are proportional gains and integral gains of the voltage loop and two current loops, respectively. The compact model of PV inverter with its controller can be expressed as

$$
\left\{\begin{array}{l}
u_{d k}=\left(K_{p d}+K_{i d} / s\right)\left(i_{d g}^{*}-i_{d g}\right)-\omega L_{f} i_{q g}+u_{d g} \\
u_{q k}=\left(K_{p q}+K_{i q} / s\right)\left(i_{q g}^{*}-i_{q g}\right)+\omega L_{f} i_{d g}+u_{q g}
\end{array}\right.
$$

\section{Configuration of Real-time Simulation System}

In comparison to performing field experiments, the real-time simulation of PV generation system 
is characterized by several merits, such as lower costs, higher flexibility and greater efficiency. A dSPACE system, with its availability to MATLAB/Simulink environment and powerful input-output interface, is quite popular in controlling platform and is widely used in automation systems and car manufacturing industries [9]. In this paper, a dSPACE DS1103 system with DSP controller TMS320F28335 configuration is proposed to realize the Hardware-in-the-loop (HIL) system, as shown in Fig. 3.

In the proposed scheme, a dSPACE system is utilized to simulate the power circuit in real time, including the PV array, inverter, step-up transformer and three-phase grid. An interface board is used to connect the dSPACE system with other devices, including the DSP controller, the host PC and the oscilloscope. During the real-time simulation, the grid-side three-phase voltage/current signal, as well as the DC-side voltage, is acquired by the DSP controller to generate the PWM signal for inverter, meanwhile this signal serves as the firing pulses for the pseudo inverter in dSPACE system through digital-input.

By utilizing the Real-Time Interface (RTI) feature available in MATLAB/Simulink environment on host PC, the real-time simulation algorithm is converted to the C-codes and simultaneously executed on the dSPACE system. Meanwhile, the host PC is capable of controlling and monitoring of the real-time system parameters with the aid of the dSPACE graphical user interface (GUI) software, ControlDesk. In order to better observe the output signals, the dSPACE input-output (I/O) library blocks are added to the real-time simulation model and D/A converter units are utilized, such that the desired signals can be visualized by an oscilloscope.

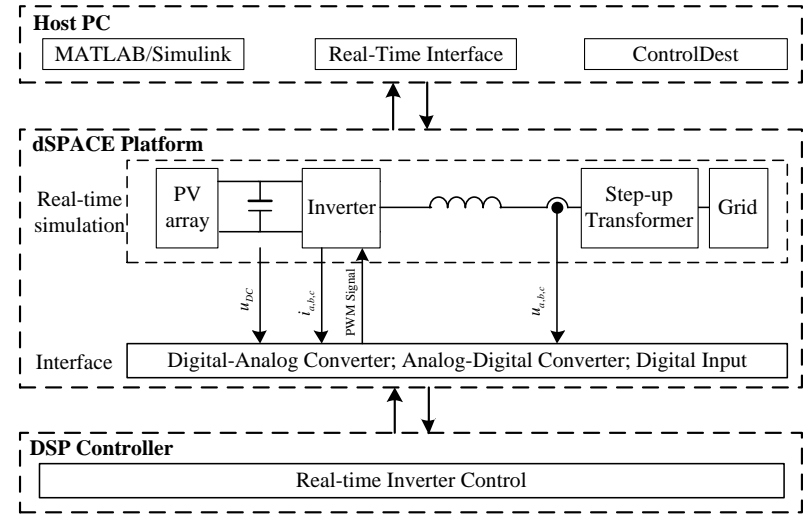

(a) Control diagram

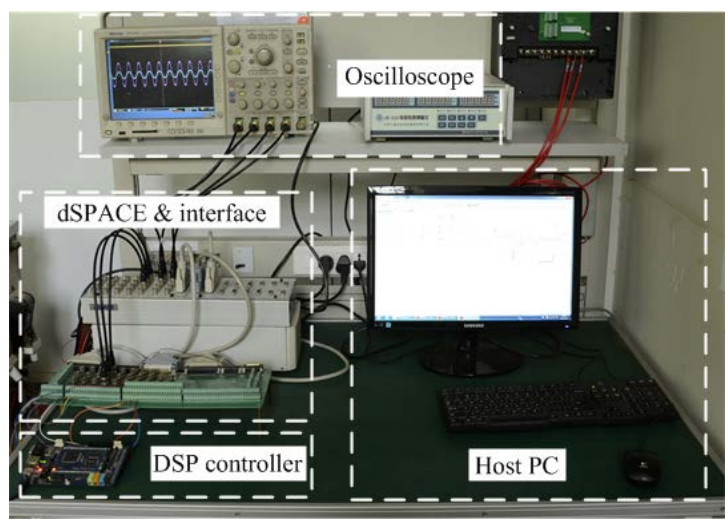

(b) experimental platform

Fig.3. Real-time PV simulation system

\section{Experimental Validation}

In order to validate the approach presented in this paper, first the steady-state operation condition of PV generation system will be tested, to examine the functional operation of system including the MPPT performance. Then, a sudden solar irradiance change is introduced in order to verify the dynamic behavior of the system. Finally, system behavior under gradual ambient temperature change is observed.

Table 1: Main parameters

\begin{tabular}{lclc}
\hline Parameters & Values & Parameters & Values \\
\hline$U_{B} / \mathrm{kV}$ & 10.5 & $L_{f} / \mathrm{mH}$ & 2 \\
$\mathrm{~S}_{\mathrm{B}} / \mathrm{kVA}$ & 100 & $X_{T} / \mathrm{pu}$ & 0.04 \\
$U_{\text {mref }} / \mathrm{V}$ & 26.2 & Resistance per unit length $/(\Omega / \mathrm{km})$ & 0.01273 \\
$I_{\text {mref }} / \mathrm{A}$ & 7.68 & Reactance per unit length $/(\Omega / \mathrm{km})$ & $9.337 \times 10^{-4}$ \\
$U_{\text {ocref }} / \mathrm{V}$ & 33.4 & Line length $/ \mathrm{km}$ & 5 \\
$I_{\text {scref }} / \mathrm{A}$ & 8.12 & Grid short circuit capacity $/ \mathrm{MVA}$ & 100 \\
Series $/$ parallel PV modules & $25 / 20$ & Grid nominal voltage $/ \mathrm{kV}$ & 10.5 \\
$C_{d c} / \mu \mathrm{F}$ & 2200 & $\mathrm{X} / \mathrm{R}$ & 10 \\
\hline
\end{tabular}


Steady-State Operation. Detailed simulation model is built in MATLAB/Simulink using the topology shown in Fig. 1 and the corresponding parameters values in Table 1. The controller parameters are given in Table 2.

Table 2: Controller parameters

\begin{tabular}{lclc}
\hline Parameters & Values & Parameters & Values \\
\hline$K_{P 1} / \mathrm{pu}$ & $0.025 \mathrm{pu}$ & $K_{I 1} / \mathrm{s}^{-1}$ & $0.3125 \mathrm{~s}-1$ \\
$K_{P 2} / \mathrm{pu}$ & 0.30 & $K_{I 2} / \mathrm{s}^{-1}$ & 20.0 \\
$K_{P 3} / \mathrm{pu}$ & 0.30 & $K_{I 3} / \mathrm{s}^{-1}$ & 20.0 \\
\hline
\end{tabular}

The proposed real-time simulation system (see Fig. 3 (b)) is utilized with step-size $8 \mu$ s. The input environmental condition is $S=750 \mathrm{~W} / \mathrm{m}^{2}$ and $T=25^{\circ} \mathrm{C}$, and the corresponding experimental results are shown in Fig. 4. It is evident that the simulated PV system operates normally in this condition, and unity power factor is achieved via inverter control.

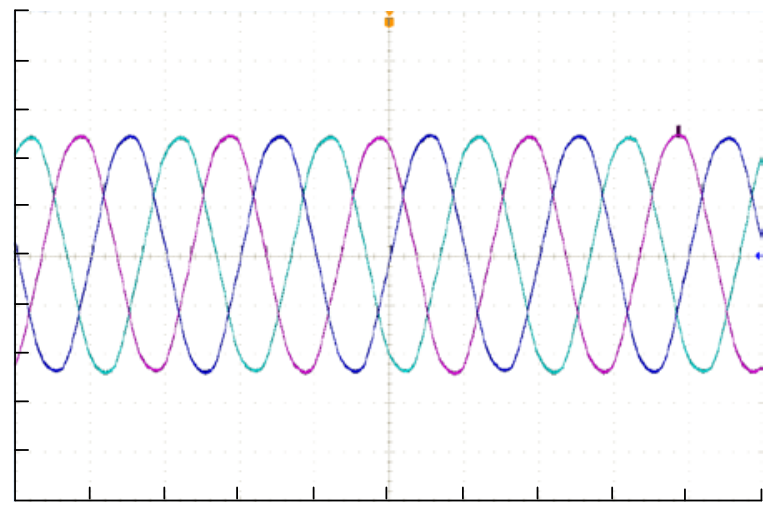

(a) Three-phase current

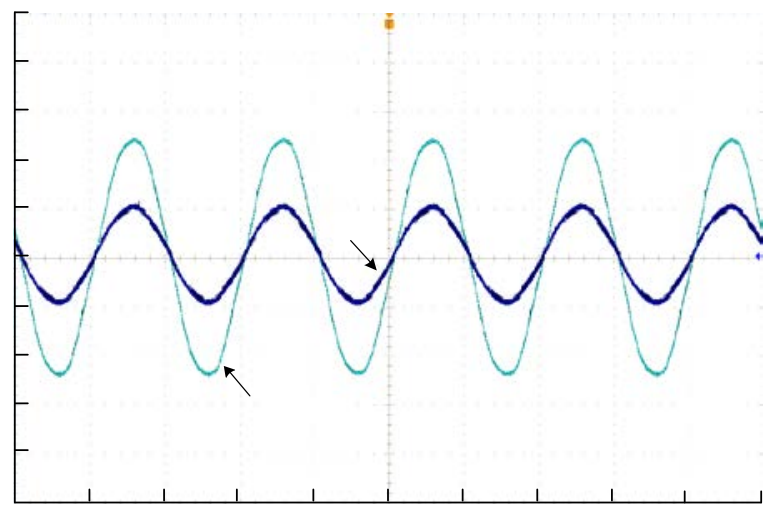

(b) voltage / current waveform of phase $a$

Fig.4. Experimental results of steady-state operation

Experimental Validation with Sudden Irradiance Change. The initial condition for simulation is $S=750 \mathrm{~W} / \mathrm{m}^{2}$ and $T=25^{\circ} \mathrm{C}$, and a sudden increase of solar irradiance of $250 \mathrm{~W} / \mathrm{m}^{2}$ occurs at $t=5 \mathrm{~s}$, causing a change in the output power and an obvious transient of DC-side voltage (see Fig. 5). The maximum output power voltage of PV arrays will change with respect to different solar irradiance, and this new value will serve as the reference signal of outer voltage loop of inverter. Dynamic process lasts roughly $0.14 \mathrm{~s}$, after which a new steady state of the system will be achieved. Meanwhile, the three-phase output voltage being virtually unaffected, the output current is proportional to the input power, leading to the increase of current.

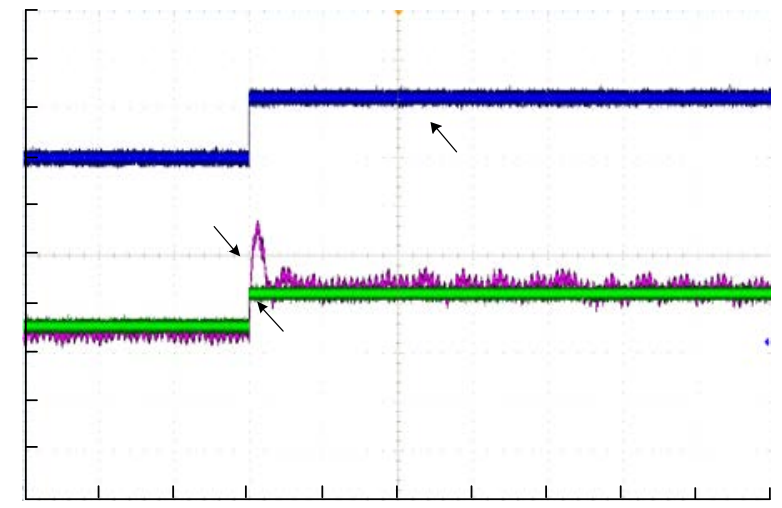

(a) DC-side voltage (reference and measured)

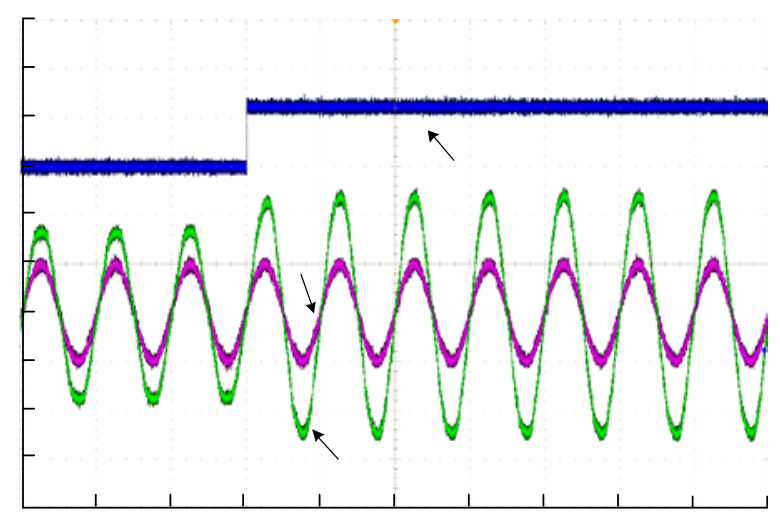

(b) voltage / current waveform of phase $a$

Fig.5. Experimental results with sudden irradiance change

Experimental Validation with Gradual Ambient Temperature Change. The experimental results with gradual ambient temperature change are illustrated in Fig. 6. It can be safely concluded 
that the maximum output power voltage of PV arrays, as well as the power generated by the entire system will be less affected compared with irradiance change.

\section{Conclusion}

In this paper, a detailed simulation model of Photovoltaic (PV) generation system is built based on MATLAB/Simulink, and its real-time simulation is achieved on dSPACE platform and DSP controller. It is shown that the switching-function equivalent model is able to improve simulation speed while preserving high precision. The proposed real-time simulation scheme is validated by assessing the system performance in normal operation and under solar irradiance/temperature disturbance.

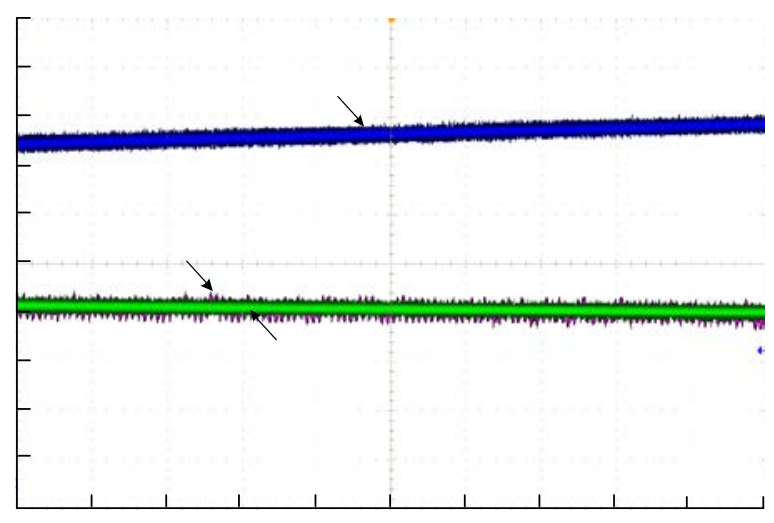

(a) DC-side voltage (reference and measured)

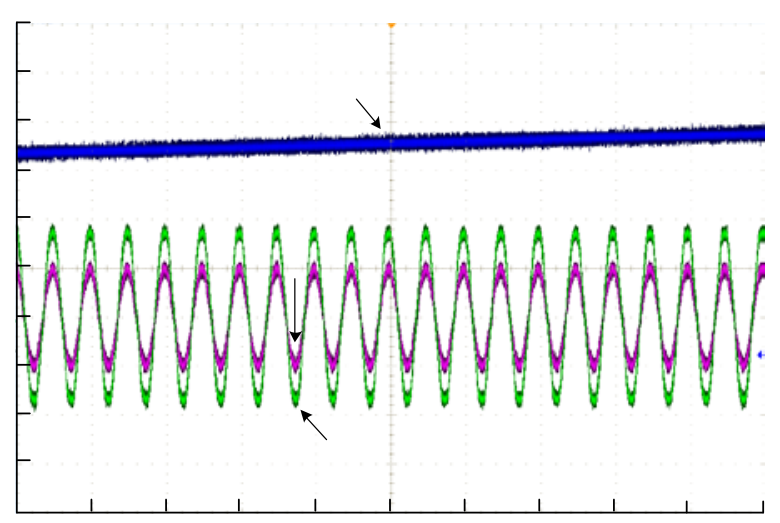

(b) voltage / current waveform of phase $a$

Fig.6. Experimental results with gradual ambient temperature change

\section{References}

[1] Estefana Caamao et al, "State-of-the-art on dispersed PV power generation: Publications review on the impacts of PV distributed generation and electricity networks.” International Energy Agency, Report, Jul. 2007.

[2] Park, Minwon, and In-Keun Yu. "A novel real-time simulation technique of photovoltaic generation systems using RTDS." Energy Conversion, IEEE Transactions on 19.1 (2004): 164-169.

[3] Ghani, Z. A., M. A. Hannan, and A. Mohamed. "Three-phase photovoltaic grid-connected inverter using dSPACE DS1104 platform." Power Electronics and Drive Systems (PEDS), 2011 IEEE Ninth International Conference on. IEEE, 2011.

[4] Varma, Rajiv K., et al. "Real-time digital simulation of a PV solar system as STATCOM (PV-STATCOM) for voltage regulation and power factor correction." Electrical Power and Energy Conference (EPEC), 2012 IEEE.

[5] S. Singer et al, "Characterization of PV array output using a small number of measured parameters,” Solar Energy, 1984, 32(5): 603-607.

[6] The MathWorks, Inc. "Universal Bridge," available at <http://www.mathworks.com/help/ physmod/sps /powersys/ref/universalbridge.html> (accessed on 1.5.2015).

[7] Jin, K. "Behavior-mode simulation of power electronic circuits." Power Electronics, IEEE Transactions on 12.3 (1997): 443-452.

[8] Lee, Byoung-Kuk, and M. Ehsami. "A simplified functional simulation model for three-phase voltage-source inverter using switching function concept." Industrial Electronics, IEEE Transactions on 48.2 (2001): 309-321.

[9] dSPACE Inc. dSPACE User Guide-Implementation Guide. dSPACE Inc, 2001. 